\section{A sociedade do espetáculo revisitada}

\section{RESUMO}

0 tema deste ensaio é o elusivo conceito teórico de espetáculo. Após mencionar como a noção foi usada por diferentes autores para descrever uma sociedade dominada por imagens, signos e inautenticidade, concentro minha atenção no muito citado (mas pouco estudado) La société du spectacle (1967), clássico em que Guy Debord traça a emergência e 0 desenvolvimento histórico de um estágio posterior do capitalismo, organizado em torno de novas formas de dominação e abstração. Na conclusão, procuro rechaçar criticamente o fatalismo das análises de Debord, dando destaque à ampla rede de movimentos artísticos e políticos contemporâneos que, inspirada pelas teses e práticas dos situacionistas, se opõe ao espetáculo globalizado.

\section{ABSTRACT}

The subject of this essay is the elusive theoretical concept of spectacle. After mentioning how the term was used by different authors to describe a society dominated by signs, images and inauthenticity, I shall focus more intently upon Guy Debord's La société du spectacle (1967) - the much cited but little read classic which traces the emergence and historical development of a later stage of capitalism organized around new forms of domination and abstraction. In the conclusion, I try to respond critically to Debord's fatalist remarks, by emphasizing a wide range of contemporary artistic and political movements that opposes the globalized spectacle inspired by the Situationists' thesis and practices.

\section{PALAVRAS-CHAVE (KEY WORDS)}

- Espetáculo (Spectacle)

- Guy Debord

- Internacional Situacionista (International Situationist)

\section{João Freire Filho}

Detentora de grande valor simbólico, a noção de autenticidade se firmou, ao longo do romantismo europeu, como um critério básico para o julgamento ético do comportamento individual e para a avaliação do mérito dos bens culturais. Opunha-se, de um lado, à divisão consciente entre ser e parecer; do outro, à criação artística pautada primordialmente por "interesses comerciais".

A reivindicação da autenticidade cultural por parte da intelligentsia européia do final do século XVIII e início do XIX expressava o mal-estar romântico diante da modernidade, avaliada como prosaica e competitiva, eivada de artificialidade na linguagem, no comportamento e na arte - o ocaso da sensibilidade e dos genuínos valores humanos. A partir de meados do século $X X$, a nostalgia da autenticidade ressurge, com singular destaque, em miríades de textos acadêmicos ou jornalísticos que buscam descrever (e censurar) a "sociedade da imagem" ou "do espetáculo" - uma sociedade onde, por todos os lados, lamentou Daniel Boorstin ([1961] 1987), "ilusões" e "pseudo-eventos" varreram da vida o "natural", o "autêntico" e o "espontâneo", a tal ponto que a própria realidade se converteu em encenação.

De acordo com o historiador norteamericano, seus compatriotas viviam num mundo onde a fantasia era crescentemente mais real do que a realidade - "Much of our interest come from our curiosity about wheter our impression resembles the images found in the newspapers, in movies, and on television. (...) We go not to test the image by the reality, but to test reality by the image (116)". Pior: o universo das representações e das tramóias midiáticas, transfigurado em referencial primário, despontava, amiúde, como mais cativante, mais sedutor do que o mundo 
concreto - "The Grand Canyon itself becomes a disappointing reproduction of the Kodachrome original" (240).

A culpa desse quadro desolador era atribuída, um tanto vagamente, às "grandes forças históricas" e aos avanços tecnológicos responsáveis por espantoso aumento na difusão de material visual (processo iniciado com a "Revolução Gráfica" da segunda metade do século XIX, que inundou de ilustrações publicações até então limitadas ao texto); a ênfase da crítica incidia, no entanto, sobre os mecanismos de consentimento popular - "Advertising men", frisou Boorstin, "are at most our collaborators, helping us make illusions for ourselves" (idem). O culto aos "pseudoeventos humanos" (as celebridades, tautologicamente definidas como "a person who is known for his well-knownness" (57)) ratificava a inconseqüência e a vacuidade do público em geral. Na conclusão, o autor sugere que a "ameaça da irrealidade" era muito maior do que a ameaça da luta de classes, da ideologia, da pobreza, da doença, do analfabetismo, da demagogia ou da tirania.

Os clamores liberais de Boorstin por uma auto-reforma dos cidadãos ("each of us must disenchant himself") inspiraram, recentemente, o conterrâneo Neal Gabler a redigir o também impactante Vida, o filme (1999). Analista cultural do New York Times e do Los Angeles Times, Gabler sustenta que a lógica do show business produziu ramificações por toda a esfera pública norte-americana: política, religião, imprensa, arte... tudo, sem exceção, se rendeu ao ritmo, às técnicas e aos truques da indústria de diversão popular. Neologismos como politainment e infotainment sinalizam a magnitude de tal submissão: nas convenções partidárias de democratas e republicanos, no jornalismo das grandes redes de TV, a palavra de ordem é atrair e manter a atenção do público, satisfazendo seu apetite pelo sensacional, pelo espalhafatoso, pela fofoca. Nostálgico, o jornalista lastima que os laços comunitários, outrora urdidos por tradições e valores morais autênticos, sejam hoje forjados por manchetes de tablóides e mexericos a respeito daqueles que fornecem entretenimento convencional (artistas, apresentadores) e daquelas pessoas que viraram "entretenimento humano" - as celebridades.

Mais do que aos efeitos dos sistemas políticos ou econômicos, devemos creditar aos efeitos corrosivos do entretenimento, no entender de Gabler, o "admirável e estranho" mundo novo em que vivemos - o "mundo da pós-realidade", onde todos nós nos tornamos atores e platéias do grandioso e ininterrupto espetáculo do "filme-vida": "De fato, Karl Marx e Joseph Schumpeter parecem ter errado ambos. Não se trata de nenhum 'ismo', mas talvez seja o entretenimento a força mais poderosa, insidiosa e inelutável de nosso tempo - uma força tão esmagadora que acabou produzindo uma metástase e virando a própria vida" (17).

Para Gabler, a "Revolução do Entretenimento" foi desencadeada durante o período otimista e festivo da belle époque, nos Estados Unidos. Naquelas paragens, o encaixe entre democracia social e estética não só insuflou a quantidade de entretenimento, desde o século XIX, como lhe forneceu apoio contra os ataques elitistas dos árbitros do gosto. Ao transformar o conceito indefinido do entretenimento em princípio explicativo geral, a perspectiva analítica de Gabler retoma, numa linguagem mais jovial, as preocupações da intelectualidade européia de meados do século XIX em diante acerca da aparente incompatibilidade (de gênios) entre a Cultura e a democracia à americana (encarada não apenas como abertura da cidadania política, mas como doutrina em que as preferências culturais de todos são potencialmente tão válidas e respeitáveis quanto às das elites tradicionais). Em apoio à sua argumentação, o autor invoca, a certa altura, um célebre lamento de Ortega y Gasset, datado dos anos 20: 
"A nota característica de nossos tempos, uma triste verdade, é que a alma medíocre, a mente rasteira, sabendo-se medíocre, tem o descaramento de reivindicar seu direito à mediocridade e sai por aí se impondo onde consegue" (28).

Não obstante efeitos de estilo e anedotas atraentes, os estudos de Boorstin e Gabler (como outros tantos, da mesma linhagem) cometem um grave equívoco: tendem a preferir a crítica impetuosa e a condenação moral à pesquisa e à reflexão sistemáticas. Fragmentários, teoricamente pouco desenvolvidos, enquadram-se dentro daquilo que Guy Debord ([1967]1997, 127-132) classificou de crítica espetacular do espetáculo - uma crítica não dialética cujo "falso desespero" era idêntico, como pensamento submisso, ao "falso otimismo" da apologia do espetáculo.

Empreendida, pioneiramente, pela moderna sociologia norte-americana, a crítica espetacular do espetáculo ostentava - nas palavras de Debord - uma índole "sinceramente reformista"; ancorada em apelos à moral, ao bom senso, à moderação, essa "boa vontade indignada" se restringia a censurar as conseqüências externas do sistema, descrevendo o espetáculo como "uma espécie de excedente negativo". Boorstin, por exemplo, teimava em contrapor, ao reino superficial das imagens (conceituado, em termos de juízo psicológico e moral, como o produto de "nossas extravagantes pretensões"), a base "normal" da sociedade - a vida privada ou a noção de "mercadoria honesta". Era incapaz de atinar que a sociedade baseada na indústria moderna não é fortuita ou superficialmente espetacular - ela é fundamentalmente "espetaculoísta" (\#14).

Conforme destaquei antes, os relatos de Daniel Boorstin e Neal Gabler nos tentam persuadir que as desventuras da sociedade norte-americana tiveram como origem, em última análise, a infeliz união - numa conjuntura "hiperdemocrática" - do exponencial desenvolvimento da velha e da nova mídia com o congenial mau gosto da massa (conceituada à Ortega y Gasset como um conjunto de pessoas não especialmente qualificadas, englobando, portanto, não apenas, nem principalmente, as "massas operárias", mas também o "homem médio") - uma legião de espectadores predisposta geneticamente a preferir "emoções baratas", "lixo sensacionalista", "apelos sensuais" e "estímulos visuais" à criação artística e à atuação política reflexiva e responsável. "É praticamente impossível resistir ao impulso de transformar quase tudo em entretenimento, quando é entretenimento que todo mundo parece querer" (111), pondera Gabler, subscrevendo, tacitamente, o já familiar argumento de defesa dos donos de empresas jornalísticas e dos marketeiros políticos.

Se os dois autores norte-americanos trataram de atualizar a longeva associação entre decadência social e cultura de massa (interpretada como o efeito cultural do processo de democratização, urbanização e industrialização) (Brantlinger, 1983), Guy Debord e seus colegas da Internacional Situacionista se dedicaram a revigorar a teoria e a prática revolucionária marxistas, no contexto da rápida modernização da França após a Segunda Guerra Mundial e da explosão do consumo nos anos 60 .

Inspirado na crítica de Marx ao trabalho alienado e ao fetiche da mercadoria, no conceito de reificação de Lukács, na teorização sobre a vida cotidiana em Lefebvre e nas reflexões da Escola de Frankfurt sobre o "mundo administrado" e a "sociedade unidimensional", Debord situa o espetáculo dentro do quadro de referência do capitalismo avançado e seu imperativo estrutural de acumulação, crescimento e lucro mediante a transformação em mercadorias de setores previamente não colonizados da vida social e da extensão da racionalização e do controle burocrático 
às esferas do lazer e da vida cotidiana.

Repetidamente evocado nas 12 edições do periódico Internationale Situationiste (1958-1969) e em vários dos panfletos da IS, o conceito de espetáculo foi elaborado, de modo mais minucioso, em La société du spectacle (1967). Sua publicação ajudou a sedimentar a posição de Debord como porta-voz da IS, e introduziu a categoria crítico-teórica central do movimento para um público mais amplo. A influência dessa obra polêmica nas atividades contestatórias de Maio de 68 não pode ser negligenciada - dois anos depois, o Le Nouvel Observateur a qualificava de "o Capital da nova geração" (Jay, 1993, 425426; Jappe, 1999, 19).

Composta de nove capítulos divididos em 221 teses, A sociedade do espetáculo é um primor de entrelinhas e subentendidos. Alterna, de maneira estratégica, um discurso puramente analítico com alusões cifradas a outros pensadores, ambigüidades poéticas e assertivas inapeláveis à moda dos manifestos das vanguardas históricas. Sua configuração traz à tona os laços estreitos de Debord e dos demais componentes da IS com os círculos artísticos do dadá, do surrealismo e do letrismo (Marcus, 1989; Kaufmann, 2001); a justificativa, porém, oferecida pelo próprio autor, a posteriori, para as ocultações, elipses e negaças de seus textos foi outra: o receio de que suas reflexões fossem pervertidas e apropriadas como uma espécie de manual por aqueles que se esforçavam para manter o sistema de dominação espetacular - "Devo ter cautela para não ensinar demais" (Debord [1988] 1997, 167).

Seja como for, tal opção estilística pode mascarar, para o leitor menos empenhado, o real escopo da análise histórica e política de Debord, além de constituir-se num convite a citações levianas. A sociedade do espetáculo integra, sem dúvida, o vasto rol das obras muito reverenciadas e pouco lidas - "De todos os que citaram este livro e o reconheceram como importante, ainda não encontrei um só que se tenha arriscado a dizer, mesmo de forma sintética, do que ele trata; para eles, o que contava era dar a impressão de que sabiam de sua existência", registra o prefácio à quarta edição italiana, lançada em 1979 (Debord [1979] 1997, 148).

Referências esparsas à teoria do espetáculo se tornaram, hoje, de rigueur nas discussões sobre a horrenda glória dos reality shows, a cobertura televisiva das campanhas bélicas norte-americanas ou a submissão das instituições e do processo político aos estratagemas do show business. Numa notável ironia histórica, Debord - sempre obstinado em conferir à sua biografia uma aura de pensador e artista maldito (cf. Debord [1989] 2002; Jappe, 1999, 67-68, 136-151) - acabou virando uma espécie de celebridade, foco de homenagens para além dos muros acadêmicos (um território, aliás, que ele se dizia orgulhoso de não habitar); seu nome é lembrado, de passagem, por exemplo, no roman-verité de Ellis $(2001,252)$ sobre o culto à moda e aos ícones midiáticos nos Estados Unidos. Tais menções honrosas costumam simplificar o conteúdo e esmaecer o radicalismo da crítica de Debord, reduzindo a noção de espetáculo à mera ferramenta descritiva acionada para festejar ou reprovar o estado hodierno da Cultura (nesse sentido, Gabler fez bem em ignorar - por completo - a obra do filósofo e agitador cultural francês, no seu Vida, o filme).

Na formulação sui generis de Debord, a "espessa bruma conceitual chamada espetáculo" (Berman et al, 1990-1991, 84) unifica e explica uma considerável variedade de fenômenos aparentes. Ao contrário do que normalmente indicam compêndios e cursos de teoria da comunicação, o autor francês não escreveu mais uma arenga contra os pecados veniais dos veículos de comunicação de massa, nos moldes das críticas efetuadas inclusive pela própria mídia, com certa regularidade 
- seja na forma bem-intencionada dos observatórios da imprensa, seja na forma auto-indulgente e hipócrita dos debates encenados por Larry King e epígonos a propósito, por exemplo, dos "abusos" no acompanhamento de casos como o julgamento de O. J. Simpson ou as infidelidades matrimoniais de Bill Clinton.

No ponto de vista de Debord, o caráter problemático dos meios de comunicação de massa não decorria de eventuais deslizes éticos, da cupidez infrene de executivos e funcionários das empresas de mídia, mas do uso generalizado dos meios de comunicação de massa como um instrumento de obstrução do diálogo - fator de integração altamente propício ao "automovimento total" da sociedade:

Se as necessidades sociais da época na qual se desenvolvem essas técnicas só podem encontrar satisfação com sua mediação, se a administração dessa sociedade e qualquer contato entre os homens só se podem exercer por intermédio dessa força de comunicação instantânea, é porque essa "comunicação" é essencialmente unilateral; sua concentração equivale a acumular nas mãos da administração do sistema os meios que lhe permitem prosseguir nessa precisa administração. (\#24)

De qualquer forma, os mass media são, para Debord, uma manifestação importante mas epidérmica destes tempos espetaculares. Numa perspectiva mais ampla e fundamental, o conceito de espetáculo se refere tanto à experiência prática da realização (sem obstáculos) dos desígnios da "razão mercantil" quanto às novas técnicas de governo usadas para avançar o empobrecimento, a sujeição e a negação da vida real e, como alertara Gramsci, conquistar o controle social por intermédio mais do consenso do que da força.
Citada na epígrafe, A essência do cristianismo (1841), de Feuerbach, descreveu como o homem se separara de sua essência, ao projetá-la num Deus - o espelho invertido da verdadeira humanidade no qual o homem venera seu próprio poder virado contra si. Essa separação generalizada engendrou a ilusão religiosa - um conteúdo profano invertido; a negação do humano onde o homem afirma como outro aquilo que nega em si mesmo. Essa ilusão chegaria ao fim uma vez que a humanidade, educada pela crítica, redescobrisse a verdade inerente em suas ilusões - sua própria essência previamente alienada na forma fantástica de Deus ou da ideologia.

A tese de que a teologia é a antropologia virada de ponta-cabeça serviu de pedra de toque para a crítica marxista da religião. Marx concordava que a religião é apenas a imagem deste mundo projetada nas nuvens; sua obra, porém, enfatizava um elemento ausente no materialismo individualista e estático de Feuerbach: a idéia de que a função da religião é reconciliar os homens com uma ordem social injusta. O desmantelamento da religião envolveria necessariamente a demolição da sociedade iníqua que lhe dava sustentação e era sustentada por ela. A liberação das ilusões teológicas e a liberação da opressão econômica formariam um único processo.

$\mathrm{Na}$ trilha do relato marxista, Debord considera o espetáculo um herdeiro ou sucedâneo da religião - a soma de "todos os subprodutos da eternidade que sobreviveram como armas no mundo dos dirigentes" (Debord [1961] 2003, 151). Trata-se de um agente de manipulação social e conformismo político, uma permanente "Guerra do Ópio" (\#44) que visa a entorpecer os atores sociais, turvando-Ihes a consciência acerca da natureza e dos efeitos do poder e da privação capitalista. O espetáculo é, em síntese, a reunião de todas as formas de representação e de produção material que 
impedem que a consciência do desejo e o desejo da consciência alcancem seu "projeto" (tal qual ele é identificado, claro, sob a ótica marxista): a abolição, por meios revolucionários, da sociedade de classes - condição histórica que permitiria a todos desenvolver a plenitude das capacidades humanas como fins em si mesmas, envolvendo-se ativamente com o mundo dos objetos, transformando-os e criando-os a partir de seu trabalho intelectual e prático.

O espetáculo de que trata Debord deve ser compreendido como um desdobramento da abstração generalizada inerente ao funcionamento da ordem capitalista. Segundo Marx, a acumulação do dinheiro, quando supera um patamar qualitativo, se transforma em capital; segundo Debord, o espetáculo é o capital em tal grau de acumulação que se torna imagem (\#34): "O resultado concentrado do trabalho social, no momento da abundância econômica, torna-se aparente e submete toda realidade à aparência, que é agora o seu produto. O capital já não é o centro invisível que dirige o modo de produção: sua acumulação o estende até a periferia sob a forma de objetos sensíveis. Toda a extensão da sociedade é o seu retrato" (\#50).

Não por acaso, pois, a visão foi privilegiada, na contemporaneidade, em detrimento de outras faculdades, como o tato; "o sentido mais abstrato e mais sujeito à mistificação" corresponde, de acordo com Debord, à abstração generalizada que informa a sociedade do espetáculo. É fácil discernir, na argumentação do autor, afinidades com o discurso antiocular formulado pelo pensamento francês, ao longo do século XX (Jay, 1993, 427-430; Jappe, 1999, 21, 173); Debord, contudo, não acalentava uma ojeriza metafísica em relação ao olhar e à imagem enquanto tais - incomodava-o, isto sim, a maneira como elas funcionam na sociedade do espetáculo. O cerne do problema estava na independência obtida pelas imagens, que escapuliam ao controle do homem. Provinham da prática social coletiva, mas se comportavam como seres reais e autônomos, motivadores de um comportamento contemplativo e mesmerizado (\#18).

Diferente do que propunha Boorstin, os cidadãos, no entendimento de Debord, contribuem para a causa da espetacularização da sociedade não devido às suas falhas morais, mas de forma compulsória, como peça das engrenagens das forças produtivas: "O homem separado de seu produto produz, cada vez mais e com mais força, todos os detalhes de seu mundo. Assim, vê-se cada vez mais separado de seu mundo. Quanto mais sua vida se torna seu produto, tanto mais ele se separa da vida" (\#33).

A institucionalização da divisão técnica do trabalho obrigou o homem a concentrar-se em atividades fragmentárias e sem sentido para ele; o produto final de seu trabalho já não lhe pertencia e, portanto, aparecia-lhe como uma força independente e hostil, fora de seu domínio. À medida que essa economia que se move por si mesma se expande, cresce a alienação que estava em seu núcleo original. Com a circulação do dinheiro (a linguagem uniforme da valoração), da mercadoria e da lógica quantitativa, um processo geral de dessubstanci alização envolve a sociedade. A economia capitalista se mostra radicalmente formal e desarraigada no que diz respeito ao mundo substantivo do valor de uso; o valor de troca e sua lei de equivalência dissolvem toda diferença qualitativa na identidade dos valores quantitativos. O dinheiro domina a sociedade como representação da equivalência geral, isto é, do caráter intercambiável de todos os bens, cujo uso permanece incomparável; como uma forma abstrata, corrosiva e disseminada, ele determina a natureza da própria realidade, e constrói o seu império sobre as fantasias e ilusões da mercadoria.

Mais e mais, o homem se converte em espectador do automovimento fascinante $e$ 
fremente das mercadorias - esse "célebre enigma metafísico", esse "fenômeno esquizóide e autocontraditório", tal qual definiu Eagleton $(1993,155)$, na esteira de Marx:

Como puro valor de troca, a mercadoria apaga de si qualquer resíduo de matéria; como um objeto aurático sedutor, ela expõe o seu próprio ser sensível singular numa espécie de espetáculo espúrio de materialidade. Mas esta materialidade é ela mesma uma forma de abstração, servindo para esconder as relações sociais concretas da sua produção. De um lado, a mercadoria espiritualiza a substância daquelas relações até fazê-las desaparecer; e de outro, investe as suas próprias abstrações com uma densidade material plausível. No seu esote-rismo, como na sua hostilidade raivosa contra a matéria, a mercadoria é uma paródia do idealismo metafísico; mas ela é também, enquanto fetiche, a forma perfeita da materialidade degradada.

Forma visível de processos sociais cujas raízes na produção humana foram esquecidas ou reprimidas, as mercadorias se oferecem ao consumidor em autonomia imediata e ganham vulto como os ídolos adorados no lugar de um Deus invisível. Não mais encaradas como um produto social do trabalho humano dotado de propriedades sensuais úteis para a vida prática das pessoas, as mercadorias passam a ser tratadas como algo naturalmente munido de faculdades, propriedades, valores e significados intrínsecos (masculinidade, feminilidade, elegância, sex appeal, ousadia, inteligência, modernidade), transferíveis ao consumidor mediante as relações místicas e abstratas de compra e posse (a mediação mágica do dinheiro) e não por intermédio das relações orgânicas do fazer e do construir (por meio da práxis) (Slater, 2002, 97, 112).
Ondas de entusiasmo por determinado produto, açuladas pela mídia, se propagam com enorme rapidez. "Vedetes do espetáculo" sobressaem como modelo de identificação, representando tipos variados de papéis e estilo de vida. O princípio do fetichismo da mercadoria se realiza completamente - na coleção de gadgets como chaveiros de brinde e outros supérfluos que foram produzidos justamente para serem colecionados verifica-se a "manifestação de uma entrega mística à transcendência da mercadoria": "O homem reificado exibe a prova de sua intimidade com a mercadoria. Como nos arroubos dos que entram em transe ou dos agraciados por milagres do velho fetichismo religioso, o fetichismo da mercadoria atinge momentos de excitação fervorosa" (\#67).

Se Marx investigou a primeira fase da dominação da economia sobre a vida social, que acarretara, no modo de definir toda realização humana, uma degradação do ser para o ter, Debord vai fixar-se numa fase posterior, em que ocorre um deslizamento generalizado do ter para o parecer, do qual todo "ter" efetivo deve extrair seu prestígio imediato e sua função última. O objeto material puro e simples dá lugar a "uma multidão crescente de imagens-objetos" (\#15), valorizada e consumida como imagem.

Dentro desse sistema de abstração, a aparência da mercadoria é mais decisiva que o verdadeiro valor de uso (sua utilidade espontânea e não mediada) e seu empacotamento simbólico gera uma indústria da imagem e uma nova "estética da mercadoria", conforme qualificou Haug ([1971] 1997). O conceito se refere, na descrição do autor marxista alemão, à maneira mediante a qual a beleza (uma "segunda pele" da mercadoria, independente de seu corpo material) é desenvolvida tecnicamente a serviço da realização do valor de troca. A construção (mediante a embalagem, a divulgação publicitária, a estética das lojas e vitrines) de uma "promessa de valor de uso", 
indispensável para impulsionar as vendas, envolve o apelo cientificamente calculado aos sentidos (à visão, sobretudo) e aos desejos e às ansiedades do consumidor, transfigurando o comércio moderno numa verdadeira "tecnocracia da sensualidade". Assim sendo, como sinalizara previamente Debord, o valor de uso (pertencente ao domínio da diferença e da diferenciação) é ressuscitado como um referente da produção: "O valor de uso que estava implicitamente compreendido no valor de troca deve ser agora proclamado de forma explícita, na realidade invertida do espetáculo, justamente porque a realidade efetiva desse valor de uso está corroída pela economia mercantil superdesenvolvida; uma pseudojustificativa torna-se necessária para a falsa vida" (\#48). Em outras palavras: o valor de troca (o domínio das identidades) ainda prevalece, mas o valor de uso é, agora, empregado de uma forma ideológica que explora as necessidades do consumidor.

O domínio espetacular está diretamente vinculado, segundo Debord, à fabricação ininterrupta de "pseudobens", "pseudonecessidades" e "pseudogozos" pelo consumo moderno, numa ruptura absoluta do desenvolvimento orgânico das necessidades sociais. $\mathrm{Na}$ fase primitiva da acumulação capitalista, a economia política se fixara nos meios e métodos de exploração do homem como operário, como força de trabalho; jamais o considerava em seus momentos de ócio, em sua humanidade. Esse ponto de vista da classe dominante se inverteu assim que o grau de abundância atingido na produção das mercadorias exigiu uma "colaboração" a mais por parte do operário. Na sociedade do espetáculo, o operário ganha uma existência fora do universo da produção; passa a ser adulado, por imperativos estruturais, como consumidor (\#43).

Segundo Debord, o sistema espetacular, que define o trabalhador como um consumidor, tenta moldar e posteriormente explorar seus desejos e suas necessidades. Como a sociedade moderna se caracteriza pela transformação em mercadoria e pela racionalização, as necessidades do homem (suas preferências e escolhas) são, elas próprias, alvos de intensa pressão social, tanto em relação à sua forma (as necessidades sempre precisam ser necessidade de mercadorias) quanto a seu conteúdo (competição por status, marketing pessoal, imagens de estilo de vida etc.). Quando as necessidades do indivíduo são determinadas pela sociedade e são definidas como necessidades de seu produto, os indivíduos simplesmente se identificam com a sociedade e consideramna satisfatória, não porque ela satisfaz suas necessidades, mas porque definiu suas necessidades em termos das satisfações que oferece (Slater, 2002, 127).

O senso da inautenticidade da vida contemporânea não suscita, em Debord, os suspiros nostálgicos característicos de conservadores, de reacionários e de certos críticos culturais de esquerda diante da integridade das sociedades prémodernas e dos supostos resquícios de sua organicidade nas atuais sociedades não-européias. Pelo contrário: a ausência de romantismo e uma dose considerável de preconceito distinguem a descrição das aldeias alinhavadas pelo autor - nada há a exaltar-se em tais unidades sociais invariavelmente "dominadas pelo conformismo, pelo isolamento, pelo controle mesquinho, pelo tédio, pelos mesmos mexericos sobre as mesmas famílias" (Debord [1988] 1997, 192-193).

Somente numa sociedade póscapitalista encontraríamos as condições de possibilidade de uma vida efetivamente autêntica. Na visão do autor, a forma política sob a qual a emancipação podia ser realizada tomara uma forma nítida, no primeiro quarto do século $X X$, nos conselhos operários revolucionários. Em contraste com o comunismo burocrático, os conselhos (ao mesmo tempo, os instrumentos de luta e a estrutura organizadora da futura sociedade liberada) 
concentravam, nos trabalhadores, as funções decisórias e executivas. Seus defensores postulavam que a organização revolucionária não podia reproduzir as condições de cisão e de hierarquia da sociedade dominante; daí a ênfase na necessidade de os cidadãos controlarem democraticamente cada esfera de suas vidas - da fábrica à comunidade. Em tais circunstâncias, por intermédio de uma intervenção coerente na história, o sujeito proletário podia emergir de sua luta contra a contemplação (\#117).

Debord conferia ao proletariado um papel bem demarcado numa construção teleológica da história - o de inimigo do espetáculo por natureza. O seu ser não fora suprimido, permanecia "irredutivelmente" existente na alienação intensificada do capitalismo moderno. Ele trazia em si "a revolução que não pode deixar nada de fora dela mesma", a exigência da dominação permanente do presente sobre o passado e a crítica total da separação (\#114). Cabia ao conjunto desses sujeitos inalienáveis e revolucionários em sua essência, em si, "instaurar a verdade no mundo" (\#221) - uma "missão histórica" que nem o indíviduo isolado nem a multidão solitária podiam realizar. A explicação para o fato de que quase todas as ações concretas do proletariado ("a imensa maioria dos trabalhadores que perdeu todo poder sobre o uso de sua vida" (\#114)) pudessem ser tachadas de "reformistas" era que ele ainda não alcançara o seu ser para si, à consciência de seu ser verdadeiro, por causa de suas ilusões e por culpa daqueles que o manipulavam em proveito próprio. De qualquer forma, continua difícil de entender como um proletariado, em si revolucionário, tenha podido, durante tantas décadas, deixar-se levar na conversa pelas "burocracias operárias" dos sindicatos e partidos... (Jappe, 1999, 118).

No prefácio à $4^{a}$ edição italiana de A sociedade do espetáculo, Debord se rejubilou ao constar que nada, na primeira versão da obra, necessitava ser corrigido, afora três ou quatro erros tipográficos "Não duvido que a confirmação encontrada por todas as minhas teses continue até o fim do século, e além dele" (Debord [1979] 1997, 152). A sociedade do espetáculo estava com os dias contados; só os tolos poderiam acreditar em algum outro desfecho menos "radicalmente realista" (idem, 162).

O próprio autor, contudo, já não se revela tão seguro assim de suas teses e previsões nos Comentários sobre a sociedade do espetáculo, redigidos em 1988. Não há, aqui, nem sombra do otimismo revolucionário e da tensão dialética da obra original. As classes médias - que Debord vaticinara que seriam absorvidas pelo proletariado ("A vitória do sistema econômico da separação é a proletarização do mundo" (\#26)) - ocupavam, agora, todo o espaço social. Suas condições de vida, de fato, se proletarizaram, em termos de privação de qualquer poder sobre sua própria existência; elas careciam, entretanto, da consciência de classe do proletariado. Não havia vestígio de nenhuma força organizada atuando contra o sistema espetacular; as únicas forças organizadas eram as que queriam sua manutenção (Debord [1988] 1997, 183).

No plano teórico, um Debord ressabiado frisa, de saída, que seus comentários não se reportam ao que é "desejável", nem "preferível" - limitam-se a registrar os fatos (169). Dentre eles, o mais significativo é o nascimento de um novo e bem mais pujante tipo de poder espetacular: o espetacular integrado, desenvolvido, de início, na França e na Itália, e que doravante tendia a imporse mundialmente. Em 1967, nosso autor distinguira duas formas (sucessivas e rivais) de domínio espetacular: a concentrada e a difusa. A primeira, ao destacar a ideologia concentrada em torno de uma personalidade ditatorial, havia acompanhado a contra-revolução totalitária na Alemanha e na Rússia. A segunda, 
ao instigar os assalariados a escolherem livremente entre uma grande variedade de mercadorias novas que se confrontavam, representara a americanização do mundo. Combinação das duas formas anteriores, o espetacular integrado, como o próprio nome antecipa, tem como característica essencial o fato de ter-se inteirado da própria realidade social e da vida cotidiana; nenhum aspecto da existência foge a seu domínio:

Quando o espetacular era concentrado, a maior parte da sociedade periférica lhe escapava; quando era difuso, uma pequena parte; hoje, nada lhe escapa. O espetáculo confundiu-se com toda a realidade, ao irradiá-la. (...) Exceto uma herança ainda considerável, mas com tendência a diminuir, de livros e construções antigas - que são, aliás, cada vez mais selecionados e considerados de acordo com as conveniências do espetáculo - já não existe nada, na cultura e na natureza, que não tenha sido transformado e poluído segundo os meios e os interesses da indústria moderna. A própria genética tornou-se plenamente acessível às forças dominantes da sociedade. (173)

Berman (Berman et al., 19901991, 82) argumenta, com propriedade, que os Comentários empobrecem, de várias formas cruciais, a tese original do espetáculo; as observações posteriores não corrigem as impropriedades do relato publicado em 1967 - na realidade, só as agravam: "Debord was both right and wrong in the original text; now he is less right and more wrong". A sociedade do espetáculo delineara, a meu ver, um retrato apropriado de certas características tendencialmente dominantes do mundo contemporâneo; ao longo do livro, no entanto, a força tendencial (e tendenciosa) do espetáculo vai ganhando intensidade e abrangência bastante discutíveis, consubstanciadas, por exemplo, nas referências-clichê ao "império da passividade moderno" (\#13) e as condições de isolamento das "multidões solitárias" (\#28). A profissão de fé no potencial revolucionário do proletariado, ratificada nas teses finais, não consegue aplacar totalmente o senso de inexorabilidade do sistema espetacular.

A atmosfera fica ainda mais lúgubre, é óbvio, com a chegada desse híbrido fatal que atende pelo nome de espetáculo integrado - nele, "as forças terríveis da rede de tirania" foram capazes não só de obscurecer a experiência concreta, ao excluí-la do sistema de representação, mas de erradicá-la inteiramente. Já não existe ágora, comunidade geral, nem comunidades restritas a grupos intermediários ou a instituições autônomas; tampouco existe qualquer lugar onde o debate de idéias possa liberar-se, de forma duradoura, da opressiva presença do discurso midiático. Já não existe o juízo - com garantia relativa de independência daqueles que constituíam o mundo erudito. Nenhum partido ou fragmento de partido tenta, sequer, manifestar a pretensão de mudar alguma coisa substancial. A construção de um presente perpétuo promove o desfazimento da memória e do sentido histórico geral (esse tema, como se sabe, reaparecerá, com outra inflexão, no centro das seminais discussões de Jameson (1997) sobre o pós-modernismo). A dissolução do pensamento lógico é deliberadamente injetada, em altas doses, na população, pelos "anestesistasreanimadores" do espetáculo (homenagem subliminar e inopinada ao cediço modelo funcionalista da "agulha hipodérmica"?).

Referências obsessivas a "sociedades veladas", arquivos confidenciais, "estatísticas incontroláveis", especialistas em vigilância, complôs, boatos programados, atividades de serviços secretos, maquinações da polícia e da "gente da mídia" só vêm reforçar a impressão de que os Comentários 
inauguram a crítica paranóica da sociedade do espetáculo. Para Berman (Berman, 1990-1991, 86), Debord parece um "Adorno tresloucado", anunciando aos quatro ventos o reino supremo do capitalismo e o fim de qualquer acesso à experiência concreta; a mim, pessoalmente, os últimos escritos do autor francês trouxeram à memória os delírios persecutórios do professor Charles Kinbote, criação impagável de Nabokov, em Pale Fire. Num plano menos anedótico, é possível afirmar que a aparente perda da crença num proletariado autônomo e vigoroso e na inevitabilidade da derrocada do capitalismo levou Debord a sucumbir, de certa maneira, ao fatalismo da arena pós-moderna. O teor de suas conclusões acerca da marcha do capitalismo ainda mantém pontos de colisão relevantes com as do último Baudrillard; o tom resignado e ominoso da argumentação, no entanto, aproxima os dois autores (Best, 1995, 6264; Best e Kellner, 1997, 118).

Debord ([1988] 1997, 191) se mostra desiludido, em especial, com os integrantes das novas gerações. Formados sob os ditames do espetáculo, eles se colocam de antemão a serviço da ordem estabelecida; desde pequenos, começam, com grande entusiasmo, pelo "Saber Absoluto da informática", enquanto ignoram, cada vez mais, a leitura, que exige um verdadeiro juízo a cada linha e é a única capaz de dar acesso à vasta experiência humana antiespetacular. "A conversação já está quase extinta, e em breve também estarão mortos muitos dos que sabiam falar" (189), profetiza, dando asas a outro lugarcomum bem do agrado de Postman (1985), Sartori (2001) \& Cia. Em A sociedade do espetáculo, o autor já atestara que o próprio conceito de juventude, no sentido de "mudança daquilo que existe", era uma espécie de anacronismo (\#62).

Fico imaginando, a propósito, qual seria a reação de Debord caso pudesse testemunhar os trabalhos de perfil político e antiinstitucional de dezenas de "coletivos" de jovens artistas brasileiros - sediados em Porto Alegre, Rio de Janeiro, Belo Horizonte, Fortaleza, São Paulo e Brasília - que se apropriam de estratégias situacionistas dos anos 60, num ataque contra a máquina da globalização neoliberal (em sintonia com as manifestações de Seattle e Gênova) e o canibalismo da produção artística pelo sistema comercial (Monachesi, 2003).

Igualmente inspirados pelos expoentes da IS, praticantes da culture jamming em todo o mundo criam e disseminam paródias mordazes de peças publicitárias e modificam drasticamente as mensagens dos cartazes e outdoors que as corporações multinacionais difundem, de forma insolente, em calçadas, prédios, ônibus, quadras de basquete e banheiros de universidade. A intenção dessa crescente rede de artistas de guerrilha é denunciar o consumismo incentivado pela mídia, o caráter invasivo do marketing das marcas globalizadas e as normas de trabalhos antiéticas adotadas, em países do Terceiro Mundo, por empresas como a Nike e a Wal-Mart.

Em vez de duas garrafas de cerveja em um banco de neve com a legenda "Frio Demais", um outdoor que parodiava a campanha da Miller apresentou a imagem de dois trabalhadores congelados em um banco de neve com os dizeres "Frio Demais: a Miller despediu 88 trabalhadores de St. Louis". O Billboard Liberation Front colou o rosto do assassino em série Charles Manson num outdoor de 11 metros da Levi's (o maior de São Francisco); na declaração deixada na cena do crime, os jammers afirmavam que tinham escolhido a foto de Manson porque os jeans eram "Costurados por prisioneiros na China e vendidos para penitenciárias nas Américas". Em 1983, a Billboard Utilizing Graffittis Against Unhealthy Promotions (BUG-UP) causou danos de US\$ 1 milhão a outdoors de tabaco dentro e nos arredores de Sidney. Nos Estados Unidos, Rodriguez Garcia (reputado como um dos mais habilidosos criadores da culture jamming) 
substituiu as mensagens de consumo das empresas de tabaco por suas próprias mensagens políticas, mais persuasivas - além de transformar meticulosamente as faces dos modelos de cigarro, de modo que parecessem doentes e repulsivos, alterou o conteúdo original do Surgeon General Warning (equivalente ao nosso "O Ministério da Saúde Adverte"): "O Diretor Nacional de Saúde adverte: Negros e latinos são os principais bodes expiatórios para drogas ilegais, e os principais alvos das drogas legais" (Klein, 2002, 307-337).

A influência da doutrinação situacionista acerca da necessidade de retomada e reformulação do espaço público e da força diruptiva do détournement ${ }^{1}$ é orgulhosamente assumida pelos culture jammers. Debord, por exemplo, é mencionado, com destaque, em editorial da revista Adbusters, principal veículo de divulgação da Adbusters Media Foundation (http://adbusters.org/magazine/23/

blueprint). Criada em 1989, a organização canadense se define como uma rede global de artistas, ativistas, escritores, fanfarrões, estudantes, educadores e empreendedores que almeja levar adiante o movimento de ativismo social da era da informação, a fim de derrubar as estruturas de poder existentes e forjar uma grande mudança na maneira como viveremos no século XXI (http://adbusters.org/information/ foundation). Idealizador e diretor da ONG, o estoniano Kalle Lasn afirma que seu objetivo era unir feministas, ambientalistas, esquerda política e jovens rebeldes, reconfigurando as forças fragmentadas das políticas de identidade em um novo e poderoso movimento de contestação (Lasn, 2000, xii).

Além de elaborar e disseminar paródias de peças publicitárias, a Adbusters coordena campanhas mundiais de conscientização como o Buy Nothing Day (conjunto de performances, marchas, protestos e détournement de ícones da cultura de consumo que visa a persuadir a população a não realizar qualquer transação comercial no dia seguinte ao Dia de Ação de Graças, quando tradicionalmente canadenses e americanos aproveitam o feriado para fazer as compras de Natal) e a TV Turnoff Week (movimento abstencionista que conclama as pessoas a desligarem seus televisores durante a semana em que as emissoras dos Estados Unidos avaliam os índices de audiência com intuito de definir preços de espaço comercial para o restante do ano).

Alguém, decerto, vai objetar que tais tentativas de usar a linguagem e a força do espetáculo contra ele mesmo podem resultar em zombaria inócua, assimilável pelo sistema. Este, porém, é um fantasma que sempre rondou todos os atos de "provocação sistemática", "abstenção espalhafatosa", "decepção radical", conforme já observara o próprio Debord ([1955] 2003, 40): “(...) [A] maior dificuldade desse projeto é mesclar propostas aparentemente delirantes com uma dose suficiente de sedução séria". Todavia, mais do que aquilatar a eficácia insurrecional dos movimentos contemporâneos anticonsumismo e anticorporações, interessa-me, por ora, registrar a circulação de um entusiasmo e de um ativismo crítico que, felizmente, não condiz com as profecias apocalípticas proclamadas nos últimos escritos do pensador francês.

Se os Comentários sobre a sociedade do espetáculo podem ser julgados essencial e irredimivelmente equivocados, a obra original continua - entre erros e acertos candentes, implacáveis, fiéis ao estilo e à personalidade de seu autor auxiliando-nos a refletir sobre os crescentes contornos mercadológicos da sociedade contemporânea. O poder de sedução das teses debordianas não deve, porém, deixar-nos hipnotizados a ponto de perder de vista o que se passa fora dos bastidores do espetáculo. Neste particular, toda a safra recente de estudos sobre a riqueza da vida cotidiana e o papel das mediações culturais na relação com a mídia; as pesquisas qualitativas e as etnografias que avaliam o 
grau de autonomia das audiências diante dos dispositivos de comunicação; as teorizações sobre consumo e cidadania podem figurar, do ponto de vista analítico, como um bem-vindo corretivo aos culs-desac a que Debord nos conduz .

\section{Notas}

1 Reunião de materiais artísticos ou midiáticos preexistentes num contexto novo, cujo impacto está diretamente relacionado à lembrança consciente ou inconsciente do contexto original dos elementos. A colagem de slogans e textos revolucionários nos balões de personagens de histórias em quadrinhos é, talvez, o exemplo mais famoso do uso dessa técnica adaptada do dadá e do surrealismo.

\section{Referências}

BERMAN, Russell et al. "The society of the spectacle: 20 years laters: a discussion". Telos, n 86 , Winter, p. 81-100, 1990-1991.

BEST, Steven. "The commodification of reality and the reality of commodification: Baudrillard, Debord, and postmodern theory". In: KELLNER, Douglas (ed.). Baudrillard: a critical reader, p. 41-67. Oxford \& Cambridge: Blackwell, 1995.

BEST, Steven e KELLNER, Douglas. "From the society of the spectacle to the realm of simulation: Debord, Baudrillard, and postmodernity". In: The postmodern turn, p. 79-123. New York: Guilford Press, 1997.

BOORSTIN, Daniel. The image: a guide to pseudo-events in America. New York: Atheneum, 1987 [1961].

BRANTLINGER, Patrick. Bread \& circuses - theories of mass culture as social decay. Ithaca \& London: Cornell University Press, 1983.

DEBORD, Guy. "Introdução a uma crítica da geografia urbana". In: JACQUES, Paola Berenstein (org.). A apologia da deriva: escritos situacionistas sobre a cidade, p. 39-42. Rio de Janeiro: Casa da Palavra, 2003 [1955].

"Perspectivas de modificações conscientes na vida cotidiana". In: JACQUES, Paola Berenstein (org.). A apologia da deriva: escritos situacionistas sobre a cidade, p. 143-152.

Rio de Janeiro: Casa da Palavra, 2003 [1961].

A sociedade do espetáculo: comentários sobre a sociedade do espetáculo. Rio de Janeiro: Contraponto, 1997 [1967].

"Prefácio à $4^{a}$ edição italiana de A sociedade do espetáculo". In: A sociedade do espetáculo: comentários sobre a sociedade do espetáculo, p. 143-164. Rio de Janeiro: Contraponto, 1997 [1979].

Comentários sobre a sociedade do espetáculo. In: A sociedade do espetáculo: comentários sobre a sociedade do espetáculo, p. 165-237. Rio de Janeiro: Contraponto, 1997 [1988].

[1989].

Panegírico. Rio de Janeiro: Conrad do Brasil, 2002

EAGLETON, Terry. A ideologia da estética. Rio de Janeiro: Jorge Zahar Ed., 1993.

ELLIS, Bret Easton. Glamorama. Rio de Janeiro: Rocco, 2001.

GABLER, Neal. Vida, o filme. Como o entretenimento conquistou a realidade. São Paulo: Companhia das Letras, 1999.

HAUG, Wolfang Fritz. Crítica estética da mercadoria. São Paulo: Ed. UNESP, 1997 [1971].

IS. Situacionista, teoria e prática da revolução. São Paulo: Conrad, 2002.

JAMESON, Fredric. Pós-modernismo - a lógica cultural do capitalismo tardio. São Paulo: Ática, 1997.

JAPPE, Anselm. Guy Debord. Petrópolis: Vozes, 1999.

JAY, Martin. "From the Empire of the Gaze to the Society of the Spectacle: Foucault and Debord". In: Downcast eyes: the denigration of vision in twentieth-century French thought, $p$. 381-434. Berkeley: University of California Press, 1993.

KAUFMANN, Vincent. Guy Debord: la révolution au service de la poésie. Paris: Fayard, 2001.

KLEIN, Naomi. Sem logo: a tirania das marcas em um planeta 
vendido. Rio de Janeiro: Record, 2002.

LASN, Kalle. Culture jam: how to reverse America's suicide consumer binge - and why we must. New York: Quill, 2000.

MARCUS, Greil. Lipstick traces. A secret history of the $20^{\text {th }}$ century. Cambridge, Massachusetts: Harvard University Press, 1989.

MONACHESI, Juliana. "A explosão do a(r)tivismo". Folha de S. Paulo, Mais!, p. 4-9, 06/04/2003.

POSTMAN, Neil. Amusing ourselves to death: public discourse in the age of show business. New York: Viking Press, 1985.

SARTORI, Giovanni. Homo videns: televisão e póspensamento. Bauru: EDUSC, 2001.

SLATER, Don. Cultura do consumo \& modernidade. São Paulo: Nobel, 2002.

VANEIGEM, Rauol. A arte de viver para as novas gerações. São Paulo: Conrad, 2002 [1967]. 